\title{
Paclitaxel, Ifosfamide and Cisplatin (TIP) Beyond Its Original Indication for Salvage Treatment of Germ Cell Tumors
}

\author{
Martin H. Voss Darren R. Feldman \\ Genitourinary Oncology Service, Department of Medicine, Memorial Sloan-Kettering Cancer Center, New York, NY, USA
}

The initial management of disseminated germ cell tumors (GCT) is well established, with such treatment, typically platinum-based combination chemotherapy $+/-$ resection of residual disease, able to achieve cure in $70-80 \%$ of patients [1-3]. An estimated $20-30 \%$ of patients, however, will experience disease-progression despite 1st line therapy or suffer recurrence of disease after an initial remission. The optimal approach in the 2nd line (initial salvage) setting remains controversial in that some investigators favor conventional-dose chemotherapy (CDCT), while others endorse high-dose chemotherapy (HDCT) programs.

The two most commonly used salvage CDCT regimens include VeIP (vinblastine, ifosfamide and cisplatin) and TIP (paclitaxel, ifosfamide and cisplatin). Each has been studied prospectively $[4,5]$ with greater efficacy reported for TIP but possibly explained by restriction to a more favorable patient population. TIP was initially developed at the Memorial Sloan-Kettering Cancer Center (MSKCC) after paclitaxel was recognized to have activity against GCT [6] and synergy in vitro with ifosfamide and cisplatin. Since analysis of outcomes to ifosfamide-based salvage CDCT indicated a very low likelihood of durable remission for patients with refractory GCT or extragonadal primary tumors, it was decided to test TIP exclusively in patients with favorable risk features. These included all of the following: 1) 1 prior treatment regimen ( $\leq 6$ cycles of cisplatin); 2) testicular primary tumor site; 3) favorable response to 1 st line therapy defined as either complete response (CR) of any duration or partial response (PR) of at least 6 months duration [5]. The CR rate amongst the 46 patients treated in this phase 2 trial was $70 \%$ with $63 \%$ long-term disease free survival (DFS) [5]. In contrast, the CR and DFS rates in the largest initial salvage VeIP trial were $50 \%$ and $24 \%$, respectively [4].

Two subsequent phase II trials also studied TIP in the 2nd line setting but with slightly inferior results [7, 8], likely attributable to less intense dosing and the inclusion of some patients with unfavorable features. Both studies administered paclitaxel at a dose of $175 \mathrm{mg} / \mathrm{m}^{2}$ rather than $250 \mathrm{mg} / \mathrm{m}^{2}$ and the study by Mead et al. also used a lower dose of ifosfamide. In this issue of ONKologie, Park et al. [9] add to the existing data by reporting their retrospective experience with TIP in 14 patients with relapsed/refractory GCT. While 11 of the 14 received TIP in the 2 nd line setting, it is important to note that none would have met the inclusion criteria used in the MSKCC study. For example, only $21 \%$ of patients reported by Park et al. had achieved a favorable response to 1st line therapy and $50 \%$ were absolutely cisplatin-refractory. Moreover, $43 \%$ of patients had extragonadal primary tumors and 3 patients were treated in either the 3rd or 4th line setting.

Despite these poor-risk characteristics, Park and colleagues report an overall response rate of $43 \%$ with at least 4 of 14 patients (29\%) achieving long-term DFS (range 25-113 months) with TIP +/- surgery. Notably, 3 of these 4 responders had platinum-refractory disease, and 1 received TIP in the 3rd line setting. A 5th patient was recurrence-free at the time of analysis, however, only 5 months removed from initiating TIP. It is also noteworthy that these results were achieved despite suboptimal dosing of paclitaxel $\left(175 \mathrm{mg} / \mathrm{m}^{2}\right.$ per cycle), and only 6 patients receiving the full 4 cycles of treatment (4 stopped early due to toxicity, possibly related to lack of G-CSF support). As mentioned above, lower dosing of paclitaxel has previously been recognized as a contributor to the inferior efficacy observed in the trials by Mardiak and Mead as compared to the MSKCC study.

At MSKCC, we risk-stratify patients in the initial salvage setting, using TIP for those with favorable features (defined above) and HDCT for those not meeting these criteria. In addition, we administer TIP to patients ineligible for HDCT due to comorbidities or those who decline HDCT. Our TI-CE HDCT program consists of 1-2 courses of rapidly recycled (every 14 days), conventionally-dosed paclitaxel and ifosfamide for stem cell mobilization followed by 3 cycles of high-

\section{KARGER}

Fax +497614520714

Information@Karger.de

www.karger.com
(C) 2011 S. Karger GmbH, Freiburg

0378-584X/11/0348-0410\$38.00/0

Accessible online at:

www.karger.com/onk
Darren R Feldman, MD

Genitourinary Oncology Service, Department of Medicine

Memorial Sloan-Kettering Cancer Center

1275 York Avenue, New York, NY, USA

Tel. +1 646422 4491, Fax +1 1219880701

Feldmand@MSKCC.ORG 
dose carboplatin plus etoposide with stem cell support. Longterm DFS with TI-CE in this unfavorable group of patients approaches $50 \%$ [10]. Other groups have also investigated prognostic models to stratify patients in the salvage setting. One such model, developed by Einhorn et al., is mentioned in this article [11]; however, it should be noted that the Einhorn score was developed by retrospective analysis of patients undergoing HDCT, and thus, does not apply in this setting. A more recent model, developed by the International Prognostic Factor Study Group (IPFSG) is applicable to both CDCT and HDCT in the 2nd line setting [12] and has emerged as the new standard, similar to the International Germ Cell Cancer Collaborative Group (IGCCCG) prognostic system for 1st line therapy [13].

With HDCT not readily available or not feasible for all patients, the study by Park et al. demonstrates applicability of TIP beyond its original indication, and adds to the existing data that long-term DFS can be achieved with TIP, even in patients predicted to have an unfavorable outcome to salvage CDCT. At MSKCC (in collaboration with the University of Southern California), we are also currently exploring alternative uses for TIP, including in the 1st-line setting as part of a phase II study for patients with IGCCCG intermediate- or poor-risk GCT.

A major remaining question in the management of GCT relates to whether there is a benefit of HDCT over CDCT for initial salvage treatment. An international randomized phase III trial, known as TIGER, has recently been proposed to answer this question by comparing TIP (at MSKCC doses) and TI-CE as initial salvage approaches. Patients will be stratified by IPFSG risk class, thus allowing for prospective evaluation of TIP for patients with unfavorable features. Therefore, this study should establish the true efficacy and clarify the role of TIP as initial salvage chemotherapy. Until then, it remains reasonable to use TIP as 2 nd line in favorable-risk patients and those ineligible for HDCT. However, we recommend using G-CSF to reduce toxicity and administering 4 cycles of TIP with full dose paclitaxel $\left(250 \mathrm{mg} / \mathrm{m}^{2}\right)$ in order to maximize efficacy.

\section{Disclosure Statement}

The authors have no conflicts of interests to disclosure.

\section{References}

${ }_{1}$ Williams SD, Birch R, Einhorn LH, Irwin L, Greco FA, Loehrer PJ: Treatment of disseminated germ-cell tumors with cisplatin, bleomycin, and either vinblastine or etoposide. N Engl J Med 1987;316:1435-1440.

$\checkmark 2$ Culine S, Kerbrat P, Kramar A, Theodore C, Chevreau C, Geoffrois L, Bui N, Peny J, Caty A, Delva R, Biron P, Fizazi K, Bouzy J, Droz J: Refining the optimal chemotherapy regimen for good-risk metastatic nonseminomatous germ-cell tumors: A randomized trial of the genito-urinary group of the french federation of cancer centers (getug t93bp). Ann Oncol 2007;18:917-924.

3 Feldman DR, Bosl GJ, Sheinfeld J, Motzer RJ: Medical treatment of advanced testicular cancer. JAMA 2008;299:672-684.

4 Loehrer PJ, Gonin R, Nichols CR, Weathers T, Einhorn LH: Vinblastine plus ifosfamide plus cisplatin as initial salvage therapy in recurrent germ cell tumor. J Clin Oncol 1998;16:2500-2504.

5 Kondagunta GV, Bacik J, Donadio A, Bajorin D, Marion S, Sheinfeld J, Bosl GJ, Motzer RJ: Combination of paclitaxel, ifosfamide, and cisplatin is an effective second-line therapy for patients with relapsed testicular germ cell tumors. J Clin Oncol 2005;23:6549-6555.
6 Motzer RJ, Bajorin DF, Schwartz LH, Hutter HS, Bosl GJ, Scher HI, Lyn P, Fischer P: Phase II trial of paclitaxel shows antitumor activity in patients with previously treated germ cell tumors. J Clin Oncol 1994;12:2277-2283.

7 Mardiak J, Salek T, Sycova-Mila Z, Obertova J, Hlavata Z, Mego M, Reckova M, Koza I: Paclitaxel plus ifosfamide and cisplatin in second-line treatment of germ cell tumors: A phase II study. Neoplasma 2005;52:497-501.

8 Mead GM, Cullen MH, Huddart R, Harper P, Rustin GJ, Cook PA, Stenning SP, Mason M: A phase II trial of TIP (paclitaxel, ifosfamide and cisplatin) given as second-line (post-BEP) salvage chemotherapy for patients with metastatic germ cell cancer: A medical research council trial. Br J Cancer 2005;93:178-184.

9 Park S, Lee S, Lee J, Park SH, Park JO, Kang WK, Park YS, Lim HY: Salvage chemotherapy with paclitaxel, ifosfamide, and cisplatin (TIP) in relapsed or cisplatin-refractory germ cell tumors. Onkologie 2011;34:416-420.
10 Feldman DR, Sheinfeld J, Bajorin DF, Fischer P, Turkula S, Ishill N, Patil S, Bains M, Reich LM, Bosl GJ, Motzer RJ: Ti-ce high-dose chemotherapy for patients with previously treated germ cell tumors: Results and prognostic factor analysis. J Clin Oncol 2010;28:1706-1713.

11 Einhorn LH, Williams SD, Chamness A, Brames MJ, Perkins SM, Abonour R: High-dose chemotherapy and stem-cell rescue for metastatic germ-cell tumors. N Engl J Med 2007;357:340-348.

12 Lorch A, Beyer J, Bascoul-Mollevi C, Kramar A, Einhorn LH, Necchi A, Massard C, De Giorgi U, Flechon A, Margolin KA, Lotz JP, Germa Lluch JR, Powles T, Kollmannsberger CK: Prognostic factors in patients with metastatic germ cell tumors who experienced treatment failure with cisplatin-based first-line chemotherapy. J Clin Oncol 2010;28:4906-4911.

13 International germ cell consensus classification: A prognostic factor-based staging system for metastatic germ cell cancers. International germ cell cancer collaborative group. J Clin Oncol 1997; 15:594-603. 


\section{Erratum}

In the printed version of the article 'Paclitaxel, Ifosfamide and Cisplatin (TIP) Beyond Its Original Indication for Salvage Treatment of Germ Cell Tumors' by Voss, M.H. and Feldman, D.R. in Onkologie 2011;34:410-411 (DOI:10.1159/000331699) there was a mistake. The first sentence of the second paragraph should read:

The two most commonly used salvage CDCT regimens include VeIP (vinblastine, ifosfamide and cisplatin) and TIP (paclitaxel, ifosfamide and cisplatin). 